УДК 81.42

DOI 10.23951/1609-624X-2020-2-37-48

\title{
ОСОБЕННОСТИ ИНТЕРПРЕТАЦИИ СВОБОДЫ В КОДЕКСЕ КАК ЯДЕРНОМ ЖАНРЕ ДИСКУРСА ПРАВОВОГО ДОКУМЕНТА
}

\section{М. А. Наземцева}

Национальный исследовательский Томский государственный университет, Томск

\begin{abstract}
Введение. Проведен анализ репрезентации концепта свобода в кодексе как ядерном жанре дискурса правового документа.

Цель - выявить специфику реализации концепта свобода, заданную модусно-диктумной организацией правового дискурса и спецификой кодекса как его ядерного жанра.

Материал и методы. Материалом исследования являются кодексы РФ, а именно Семейный, Трудовой, Жилищный, Гражданский и Уголовный. Выборка материала обусловлена ядерным статусом кодекса в правовом тексте. Являясь одним из основных документов правового дискурса, кодекс наряду с Конституцией РФ отражает основы права. Свобода как ключевой концепт русской культуры по-особому репрезентируется в правовом дискурсе. Методология представлена дискурс- и концепт-анализом: дискурсивные и жанровые особенности определяются с позиции кодекса в жанровой системе правового дискурса, свобода анализируется через сравнение данного концепта в системе русской языковой картины мира в целом (на материале уже проведенных исследований) с правовым дискурсом в частности.

Результаты и обсуждение. Обнаружено, что концепт свобода, в отличие от его обыденного представления в русской языковой картине мира, имеет особую небинарную специфику и трансформируется с помощью закона. В обыденном сознании существует оппозиция свобода (воля) / несвобода, в кодексе свобода реализуется посредством разрешительного (то, что можно делать в рамках закона), запретительного модуса (то, что уголовно наказуемо и предписано через несвободу, т. е. арест), а также модуса долженствования (то, что по закону должно быть совершено). Кроме того, свобода в кодексах определяется их тематической сферой: существует свобода семейных, трудовых, жилищных, гражданских и др. отношений. В оппозиции находится то, что делать запрещено и гарантирует несвободу (представлено Уголовным кодексом).

Заключение. Свобода в дискурсе правового документа - официально зафиксированная возможность человека действовать в рамках закона. Кодекс как ядерный жанр правового дискурса осуществляет преобразование концепта посредством его модусно-диктумной модификации. В результате определяющим средством для реализации концепта свобода является закон, а также основные концепты каждого выбранного кодекса - семья, труд, жилище, гражданин, наказание.
\end{abstract}

Ключевые слова: концепт «свобода», русская языковая картина мира, дискурс правового документа, жанр кодекс, диктум и модус дискурса.

\section{Введение}

Свобода в русской языковой картине мира является ключевым концептом (Т. Г. Ардашева, В. Н. Базылев, Т. В. Булыгина, А. Д. Шмелев, А. Вежбицкая, О. С. Егорова, О. А. Кириллова, А. Г. Лисицин, Н. М. Петровых, А. С. Солохина, И. Б. Щеболева и др.), структуру и содержание которого исследователи характеризуют следующим образом.

Во-первых, концепт бинарен и предполагает оппозицию свобода/несвобода [1-3 и др.]: свобода в сознании носителей языка имеет границы, которые определяются наличием несвободы.

Во-вторых, свобода ассоциируется с достижением положительных ощущений легкости, непринужденности, комфорта и счастья, а значит, оценивается положительно [4, 5 и др.]. При этом излишняя свобода вызывает негативное оценивание субъектов свободы извне, отклоняющихся от групповых норм [3, с. 12].

Общекультурное содержание концепта в зависимости от дискурсивной сферы его реализации приобретает особую дискурсивно обусловленную конфигурацию [6 и др.].

Материалом для статьи послужили тексты кодексов РФ: Семейный (СК) [7], Трудовой (ТК) [8], Жилищный (ЖК) [9], Гражданский (ГК) [10] и Уголовный (УК) [11] кодексы. В качестве сравнительного фона привлекался текст Конституции РФ (К) [12], также рассматриваемой как жанровая форма реализации правового дискурса.

Объектом исследования являются тексты кодексов РФ как продукт особой жанровой реализации правового дискурса, а предметом - специфика представления в них концепта свобода.

Актуальность работы обусловлена интересом к особенностям дискурсивной реализации общекультурных концептов, в том числе концепта свободa, занимающего одну из ключевых позиций в русской языковой картине мира, а также ее обращенностью к исследованию специфики речевой организации правового дискурса. Новизна исследования заключается, во-первых, в представлении 
результатов анализа исследуемого концепта в правовом дискурсе, который практически не описан в современных работах (за исключением отдельных наблюдений А. Вежбицкой [4], Т. Г. Ардашевой $[13,14]$ и А. Х. Мерзляковой [14]), во-вторых - в выборе объекта исследования: кодекс как жанр правового дискурса в современных лингвистических исследованиях не описан.

Лингвистические исследования правового дискурса немногочисленны [15-19 и др.]. Наиболее подробно описаны отдельные признаки текстовой организации Конституции РФ [20-30].

Впервые результаты анализа национально-культурной специфики правового содержания исследуемого концепта представлены в работе А. Вежбицкой [4]. В частности, в отдельных работах на материале Конституции ученые обращаются к выявлению специфики реализации рассматриваемого нами концепта [14].

Если текст Конституции уже становился объектом внимания лингвистов, в том числе в жанровом аспекте, то, как уже отмечалось, кодекс как жанр правового дискурса в зону внимания лингвистического анализа не попадал. При его изучении мы опирались на работы юристов, обсуждавших теорию и проблематику принципов кодификации в правовой системе [31]. Наиболее подробный анализ правового дискурса с позиций юриспруденции представлен в работах Н. Г. Храмцовой [32-41].

\section{Материал и методы}

Методология данной работы основана на теории дискурс-анализа. Мы опираемся на постулат о том, что дискурсивная картина мира отражает национально-культурный концепт в его дискурсивной динамике [6, с. 24]. В связи с этим дискурсивная картина мира является результатом дискурсивно обусловленного реконфигурирования общенациональных концептов, осуществляемого при реализации дискурсивно-жанровых целей.

В данном исследовании кодекс рассматривается как ядерный жанр дискурса правового документа, что определяет специфику реализации рассматриваемого концепта.

Цель статьи - выявить специфику реализации концепта свобода, заданную модусно-диктумной организацией правового дискурса и спецификой кодекса как его ядерного жанра.

Для ее выявления рассмотрим особенности дискурса правового документа, входящего в правовой дискурс, в рамках которого кодекс выступает как ядерный жанр, а также специфику дискурсивножанрового представления исследуемого концепта в кодексе.

Выявление особенностей дискурса правового документа, влияющих на реализацию исследуемо- го концепта, мы осуществляем на основании концепции модусно-диктумной организации содержания дискурса, представленной в работе И. В. Тубаловой [42]. В основе данной концепции лежит положение о том, что «в содержании дискурса представляется возможным ... выделить объективнофактологический компонент - дискурсивный диктум - и интенционально обусловленную позицию дискурса по отношению к нему - дискурсивный модус» [42, с. 100]. Данная логика предполагает переосмысление разработанных в рамках семантического синтаксиса терминов «диктум» и «модус» как составляющих коммуникативной структуры предложения, заданных в концепциях Ш. Балли, В. В. Виноградова и получивших подробную разработку в работах современных ученых (Т. В. Шмелевой, Е. В. Падучевой и др.)

Интерпретируя понятие «модус» применительно к высказыванию, Т. В. Шмелева отмечает, что «в модусе проявляется субъективность „в интересах говорящего“: отношения и оценки говорящего, основанием для которых служат положение автора относительно описываемых событий, его представления о достоверности той или иной информации, его „система ценностей““ событий и т. п.» [43, c. 81]. В работе И. В. Тубаловой понятие «модус дискурса» используется на основании данной логики, но в другом значении: «в нем выражается социально заданная специфика дискурсивного поведения субъекта, участвующего в дискурсивных практиках, вступление в которые вынуждает его транслировать оценки и ценности с учетом „дискурсивной власти“» $[42$, с. 52]. В связи с этим понятие «дискурсивный модус» соответствует понятию «модус высказывания/предложения» в аспекте (1) его участия в выражении интенциональности, (2) противопоставленности его интерпретационного смысла объективно-фактологическому. Но эти понятия кардинально расходятся в аспекте субъекта этой интенциональности: по отношению к конкретному говорящему модус дискурса является социально объективированным, «рамочным» смыслом, который он вынужден учитывать при реализации собственной частной цели» [42]. Таким образом, формирование дискурсивного модусного смысла определяется не интенцией говорящего субъекта, а целью дискурса, определяющей социально заданный тип дискурсивного осмысления действительности, в данном случае - его осмысления, заданного в дискурсе социального института права.

Целью правового дискурса является государственно-правовое регулирование [41, с. 120, 125]. По каналу связи правовой дискурс делится на письменный и устный [41, с. 182-183]. Кодекс входит в состав письменных форм его реализации - правовых документов. 
Правовая деятельность организована таким образом, что любые ее практики опираются на правовой документ как форму официализации правового дискурсивного смысла и источник правового дискурсивного смыслообразования. В связи с этим письменная форма правового дискурса занимает более высокую ступень в дискурсивной иерархии смыслов по отношению к устной: письменные правовые документы определяют деятельность, реализуемую в устной форме, а устная при ее реализации опирается на письменную (на тексты законов). На вершине этой иерархии находится Конституция (основной закон), далее - прочие законы и кодексы (федеральные конституционные законы, постановления Конституционного Суда, другие федеральные законы), далее - остальные правовые документы (указы Президента, акты Правительства, нормативные акты министерств и ведомств, региональные нормативные акты и др.) [44, c. 158].

$\mathrm{B}$ соответствии с иерархией дискурсивного правового смыслообразования кодекс, являясь регулятором права, составляет жанровое ядро дискурса правового документа и правового дискурса в целом и опирается на Конституцию.

Диктумное содержание дискурса правового документа составляет совокупность представлений о социальной действительности, подлежащих правовому документированию.

В правовом дискурсе в качестве базового можно выделить модус правовой оценки, являющийся результатом дискурсивного переосмысления этической оценки, значимой для интерпретации свободы как общекультурного концепта.

В дискурсе правового документа его материализация, закрепленная в стабильных текстовых формах, обнаруживает действие модусов дискурса документа, с которым правовой дискурс взаимодействует на уровне целей.

Мы, вслед за И. В. Тубаловой, определяем базовый модус дискурса документа как модус официальности [42, с. 240]. На этом основании модус дискурса правового документа определяется как модус официальной правовой оценки типовая ценностная установка правового дискурса, представляющая все объекты правовой интерпретации как обязательные для гражданина в силу их законодательной закрепленности. Письменная форма и социальный статус правового документа выступают при этом как формы его реализации. Таким образом, в дискурсе правового документа происходит официальная правовая обработка и письменная фиксация этико-моральных принципов, и в результате они предъявляются клиентам дискурса как обязательные к исполнению.

\section{Результаты и обсуждение}

Правовой дискурс представляет права и свободы человека через перечень разрешенных законом действий гражданина и государства (прав и свобод), проявляющихся через предикаты может, свободен, имеет право и пр., запретов на совершение запрещенных законом действий (ограничивающих права и свободы), проявляющихся через предикаты запрещается, запрещен, не допускается и др., а также необходимых, с точки зрения закона, действий (обязанностей), проявляющихся через предикаты должен, обязан и пр.

Результат дискурсивного конфигурирования концепта свобод $a$, вербализующийся в описаниях ограниченных законом и разрешенных им видов активности гражданина и государства, которые диктуют четкие границы свободы, составляет модусно ориентированный дискурсивный диктум.

В том, что в кодексе закрепляется наличие у гражданина не только прав и свобод, но и обязанностей, проявляется заданная на национально-культурном уровне бинарность исследуемого концепта.

Модус официальности дискурса правового документа конкретизируется «в модусах императивности (закон для всех обязателен) и объективности (источник императивности предъявляется как некоторая объективная инстанция)» [42, с. 316].

Модус объективности в дискурсе правового документа проявляется в том, что в качестве объективной инстанции, задающей границы свободы и гарантирующей ее в рамках установленных границ, выступает закон, определяющий равенство всех граждан при его исполнении: Граждане Российской Федерачии ..., совершивщие вне пределов Российской Федераиии преступление против интересов, охраняемых настоящим Кодексом, подлежат уголовной ответственности в соответствии с настоящим Кодексом (УК)).

Модус императивности проявляется в представлении положений закона как обязательных к исполнению. В исследуемом дискурсе в соответствии с особой организацией субмодуса императивности содержание концепта свобода приобретает более сложную организацию, чем в общенациональной картине мира, уточняющую отмеченное выше соответствие общекультурно заданной бинарной организации концепта: (1) свобод $a=$ «разрешено» / (2) несвобод $a=(2.1)$ «запрещено» + (2.2) «обязан». При этом важно, что даже «разрешение» быть свободным вербализуется в императивном регистре.

Специфика жанровой интерпретации свободы в кодексе выявляется при его сравнении с Конституцией.

Функциональное распределение жанров правового документа зависит от их юридического статуса, определяющего их дискурсивный статус: у 
Конституции он выше, чем у кодекса, поскольку она является основным государственным правовым документом. Жанровые интенции правового документа образуют иерархию, согласно которой Конституция занимает положение дискурсивного источника правового регулирования.

Кодекс наряду с Конституцией является ядерным жанром дискурса правового документа. Целью кодекса является фиксация принципов практического правового применения заданной в Конституции правовой идеологии РФ.

В соответствии с этим заданное в Конституции обобщенное диктумное содержание конкретизируется в кодексах в соответствии с той сферой существования гражданина, на правовую оценку которой они направлены (СК - семейная, ТК - трудовая, ЖК - жилищная, ГК - гражданская, УК - уголовная и т. д.). Основными концептами, составляющими диктум кодексов, становятся соответствующие концепты: семья, труд, жилье, гражданин, наказание и др.

Принципы конкретизации диктумного содержания Конституции в кодексах, во-первых, предполагают фиксацию конкретных правовых и неправовых действий гражданина и государства, соответствующих соблюдению/нарушению заданных законом границ их свободы. Например, обобщенное описание возможностей и обязанностей родителей как одного из правовых статусов гражданина, представленное в соответствующем разрешительно-долженствующем высказывании Конституции Забота о детях, их воспитание - равное право и обязанность родителей (К), в СК конкретизируется за счет фиксации в разрешительных высказываниях конкретных прав ребенка: Ребенок имеет право на защчиту от злоупотреблений со сторонь родителей (лии, их заменяющих) (СК) и т. д.

Во-вторых, в Конституции, представляющей идеальный образ гражданина и государства, информация о реакции на его неправовые действия практически отсутствует. В кодексе конкретность представления правовых/неправовых действий, соответствующих соблюдению/несоблюдению границ свободы, позволяет представить заданные законом реакции на них - наказания. Например, это может быть реакция на нарушение приведенных требований СК (Родители (один из них) могут быть лишень родительских прав, если они:... злоупотребляют своими родительскими правами (CK)). Таким образом, кодекс не только конкретизирует зафиксированный в Конституции идеальный образа гражданина и государства в конкретной правовой сфере, но и отражает принципы правовой оценки его нарушения.

Любые ограничения, вводимые государством с помощью закона, в кодексе, как и в правовом ди- скурсе в целом [45, 46 и др.], мотивируются этически. При этом в Конституции как документе, идеологически значимом для мотивировки этического обоснования закона, на уровне дискурсивного стиля активно проявляется пафос как форма реализации эмоционально ориентированного представления этических ценностей [42, с. 182, 195]: соединенные общей судьбой на своей земле // исходя из общепризнанных приничипов равноправия и самоопределения народов, чтя память предков, передавиих нам любовь и уважение к Отечеству, веру в добро и справедливость // возрождая суверенную государственность России и утверждая незыблемость ее демократической основы, стремясь обеспечить благополучие и процветание России // исходя из ответственности за свою Родину перед нынешним и будущчими поколениями (К). В кодекcax пафос стремится к нейтрализации, что соответствует конкретике выражаемого диктума. Но в текстах кодексов, структурно организованных как представление диктума от общего к частному, в наиболее обобщенных высказываниях, задающих границы свободы, сохраняется прямая отсылка к этическим ценностям. Она выражается через номинирование этически значимых, эмоционально заряженных на уровне национальной культуры категорий нравственность, жизнь, здоровье, природа, культура и пр. В кодексе они вводятся с помощью стандартизованных фразообразований, построенных по модели «права могут быть ограничены, если это необходимо для обеспечения...»: Права граждан в семье могут быть ограничены только на основании федерального закона и только в той мере, в какой это необходимо в целях защчить нравственности, здоровья, прав и законных интересов других членов семьи и иных граждан (СК) и др.

В кодексах описание границ свободы приобретает большую конкретику, чем в Конституции, что выражается в характеристике не только общих принципов правового существования гражданина, но разрешенных/запрещенных ему законом действий, а также возможных наказаний. В связи с этим если в Конституции состав лексических репрезентантов исследуемого концепта в основном ограничивается такими номинациями, как свобода, право, возможность (и их словообразовательными коррелятами), описывающими предоставленные законом возможности гражданина, то в кодексах этот состав расширяется за счет номинаций, описывающих допускаемые законом интенции гражданина: интерес, усмотрение (обеспечение приоритетной защиты прав и интересов несовершеннолетних $и$ нетрудоспособных членов семьи (СК). Если в Конституции номинация интерес (конструкция «в интересах...») фиксируется единично, то, например, в СК данная номинация устанавливается около 
Наземиева М. А. Особенности интерпретации свободы в кодексе как ядерном жанре дискурса...

90 раз. Номинация усмотрение (конструкция «по усмотрению...») в Конституции не фиксируется, но появляется в текстах кодексов.

Специфика диктумного содержания каждого конкретного кодекса влияет на дискурсивный стиль, используемый при реализации исследуемого концепта. Например, в соответствии с ним конкретизируются номинации пользователей свободы, представленные в Конституции как обобщенные (наиболее частотная номинация пользователя свободы в Конституции - гражданин): например, в СК - супруги, родители, ребенок, органы опеки и др., ТК - работник, работодатель, трудовой инспектор и др., в ЖК - собственник и др., в ГК правообладатель, участник гражданских правоотнотений и др., в УК - нарушитель и др. Пафос, свойственный дискурсивному стилю Конституции, в кодексах нейтрализуется.

Тип диктумного содержания кодекса определяет соотношение и характер высказываний, реализующих субмодусы модуса императивности - (1) разрешительный, (2) запретительный и (3) субмодус долженствования, при реализации которых эксплицируется концепт свобода.

Если в Конституции - в соответствии с ее жанровыми целями (1) презентовать права и свободы человека как закрепленные законом основания действующих правовых норм ( $\mathrm{Mbl}$, многоначиональный народ Российской Федерачии /.../, утверждая права и свободы человека, гражданский мир и согласие, принимаем КОНСТИТУЦИЮ РОССИЙСКОЙ ФЕДЕРАЦИИ (К)), а также (2) идеологически мотивировать граждан на соблюдение закона - доминирующую роль играет разрешительный субмодус (реализующие его высказывания составляют 54,45 \%: например Каждый имеет право на образование (К)), меньшую активность проявляет запретительный субмодус (31,94 \% высказываний: например Цензура запрещает (К)) и наименее частотно реализуется субмодус долженствования (13,61 \% высказываний: например Каждый обязан заботиться о сохранении исторического и культурного наследия, беречь памятники истории и культуры (К)), то в кодексах это соотношение меняется в соответствии с диктумным содержанием каждого кодекса.

Рассмотрим это соотношение. Определим в соответствии с ним содержательные составляющие исследуемого концепта.

Разрешительный субмодус играет доминирующую роль в СК (реализующие его высказывания составляют 70,38 \%), ТК $(55,41 \%)$, ЖК $(58,97 \%)$ и ГК $(49,74 \%)$, причем в наибольшей степени на описание перечня разрешенных действий («свобод») ориентировано правовое регулирование существования семьи как сферы, наименее потенци- ально «опасной» для жизнедеятельности других граждан. В ГК, например, их значительно меньше, так как в нем представлено регулирование жизнедеятельности граждан, более значительно связанной с обеспечением их правовой безопасности (финансовой и др.).

По этой же причине в СК примерно равное количество высказываний, реализующих субмодусы долженствования $(14,94 \%)$ и запретительный $(14,68 \%)$. Долженствование превалирует над запретом в ТК (31,04 и 13,55\% высказываний соответственно), ЖК (29,40 и 11,63\%), и ГК $(36,81$ и $13,45 \%)$, и в каждом из них субмодус долженствования проявляется значительно более активно, чем в СК. Правовая «несвобода» по отношению к семейным отношениям в целом менее активна.

Кардинально отличается рассматриваемое соотношение в тексте УК, где доминирующую роль играет запретительный субмодус (реализующие его высказывания составляют 71,80 \%), значительно меньшую активность проявляет разрешительный субмодус $(26,67$ \% высказываний) и наименее частотно практически не реализуется субмодус долженствования (1,53 \% высказываний). Такое соотношение определяется диктумной ориентацией УК на регулирование наиболее потенциально опасных для других граждан действий и описание реакции закона на них (наказаний).

Рассмотрим содержательные составляющие исследуемого концепта в кодексах, выраженные высказываниями каждого субмодусного типа.

(1) Разрешительный субмодус обнаруживается в 52,234 \% модусных высказываний рассмотренных текстов кодексов.

Основными содержательными составляющими исследуемого концепта, реализуемыми в разрешительных высказываниях, являются (1.1) свобода как возможность субъекта права осуществлять разрешенные законом действия и (1.2) свобода как возможность субъекта права в особых условиях не осуществлять требуемые законом действия.

(1.1) Свобода как возможность субъекта права осуществлять разрешенные законом действия.

В качестве субъектов получения (пользователей) свободы в таких высказываниях выступают как граждане (Военнослужащий, впервые совершивший дезертирство, предусмотренное частью первой настоящей статьи, может быть освобожден от уголовной ответственности, если дезертирство явилось следствием стечения тяжелых обстоятельств (УК)), так и официальные государственные органы (Суд может с учетом интересов ребенка принять решение об отобрании ребенка у родителей (одного из них) без лишения их родительских прав (ограничении родительских прав) 
(CK)), что подчеркивает их равенство перед закоHом.

В каждом кодексе - в соответствии с его диктумной спецификой - характер разрешений приобретает содержательно обусловленные основания. Приведем примеры этих оснований.

Для СК актуализируются, во-первых, принципы добровольности и взаимного согласия при формировании семьи (Регулирование семейных отномений осуществляется в соответствии с принциипами добровольности брачного союза мужчины $и$ женщины, равенства прав супругов в семье, разрешения внутрисемейных вопросов по взаимному согласию... (СК)) и, во-вторых, возможность действовать свободно в кругу семьи (Супруги по своему желанию выбирают при заключении брака фамилию одного из них в качестве общей фамилии... (CK)).

В ТК свобода выражается в возможности выполнения действий, определенных трудовым законодательством: Если в период испьтания работник придет к выводу, что предложенная ему работа не является для него подходящей, то он имеет право расторгнуть трудовой договор по собственному желанию, предупредив об этом работодателя в письменной форме за три дня (ТК).

В ЖК данный смысловой компонент проявляется через свободу обращения с жилищными правами: Граждане по своему усмотрению и в своих интересах осущуествляют принадлежащуие им жилищные права, в том числе распоряжаются ими (ЖK).

(1.2) Свобода как возможность субъекта права в особых условиях не осуществлять требуемые законом действия.

В качестве субъектов получения (пользователей) свободы в таких высказываниях выступают граждане. Цель высказываний - зафиксировать условия освобождения от отдельных обязанностей (свобода - отсутствие обязанностей, допустимое при определенных заданных законом условиях): Дети освобождаются от уплаты алиментов родителям, лишенным родительских прав. (СК) // ... работники не должны отказываться от своих прав на сохранение и защитту тайны (ТК) // Граждане, признанные в установленном настояшим кодексом порядке малоимущиими гражданами и занимающие жилье помещуения по договорам социального найма, освобождаются от внесения платы за пользование жильм помещением (платы за наем) (ЖК) // Завещзатель не обязан сообщать кому-либо о содержании, совершении, об изменении или отмене завещзания (ГК) // Лицуо, совершивмее преступление иной категории, освобождается от уголовной ответственности только в случаях, специиально предусмотренных соответствуюшими статьями Особенной части настоящуего Кодекса (УК).

Отметим, что в УК нет формулировок «не должен» и «не обязан», в данном кодексе перечислены лишь основания для освобождения от обязанности: Лицу, впервые совершивщее преступление небольшой или средней тяжести, освобождается судом от наказания, если будет установлено, что вследствие изменения обстановки это лицьо или совершенное им преступление перестали быть общественно опасныли (УК). В этом случае разрешение выражается через указание на отсутствие обязанности/запрета и отражает конкретность диктумного содержания кодекса (в сравнении с Конституцией), ориентированную на его применение в правовых практиках (указание на особые условия реализации свободы).

(2) Запретительный субмодус реализуется в 25,022 \% модусных высказываний рассмотренных текстов кодексов.

В запретительных высказываниях содержание исследуемого концепта предстает как то, что в результате нарушения закона может быть ограничено извне и конкретизируется в кодексах в соответствии с их диктумной спецификой: Запрешуаются любые формы ограничения прав граждан при вступлении в брак и в семейных отношениях по признакам сочиальной, расовой, нацчиональной, языковой или религиозной принадлежности (СК) // Запрещзается необоснованный отказ в заключении трудового договора (ТК) // Членом правления товарищества собственников жилья не может являться лицо, с которым товарищество заключило договор управления многоквартирнылм домом (ЖК) // Не допускаются осуществление гражданских прав исключительно с намерением причинить вред другому лищу, действия в обход закона с противоправной целью, а также иное заведомо недобросовестное осущуествление гражданских прав (злоупотребление правом) (ГК).

Специфика ТК состоит в том, что если в Конституции и других кодексах указывается, что гражданин не может быть ограничен в своих правах на перечисленных ниже основаниях, то в ТК фиксируется также, что он не может получать какиелибо преимущества: Никто не может быть ограничен в трудовых правах и свободах или получать какие-либо преимущества в зависимости от пола, pacbl, цувета кожи, национальности, языка, происхождения..., а также от других обстоятельств, не связанных с деловыли качествами работника (TK).

Важность, абсолют прав, свобод и законных интересов подчеркивается тем фактом, что их нарушение наказывается. Список наказаний указан в 
Наземиева М. А. Особенности интерпретации свободы в кодексе как ядерном жанре дискурса...

УК, поэтому запретительный субмодус наиболее актуален для интерпретации диктума УК: Дискриминачия, то есть нарушение прав, свобод и законных интересов человека и гражданина в зависимости от его пола, расы, национальности, языка, происхождения..., наказывается... лишением свободы на срок до двух лет (УК). Такая формулировка позволяет использовать текст кодекса для практического применения в судопроизводстве.

УК не предоставляет список прав и свобод человека и гражданина, он косвенно реализует их через перечень того, что гражданину запрещено. Вводится понятие наказания: Наказание есть мера государственного принуждения, назначаемая по приговору суда. Наказание применяется к лииу, признанному виновныл в совершении преступления, и заключается в предусмотренных настоящии Кодексом литении или ограничении прав и свобод этого лиича (УК).

(3) Субмодус долженствования реализуется в 22,744 \% модусных высказываний рассмотренных текстов кодексов.

Основными содержательными составляющими исследуемого концепта, реализуемыми в высказываниях долженствования, являются следующие.

(3.1) Свобода - то, что должны защищать официальные инстанции: данное значение проявляется в высказываниях, формулирующих обязанности государственных органов по отношению к гражданину. В кодексе оно также конкретизируется в зависимости от особенностей диктума каждого, поэтому по большей части проявлено в целях и задачах кодексов (для СК должны соблюдаться семейные права, для УК - предоставляться мир и безопасность, для ЖК - соблюдение прав и свобод владения жильем и т. п.): Семья, материнство, отиовство и детство в Российской Федераиии находятся под защитой государства (СК) // Основными принципами правового регулирования трудовых отношений ... признаются: обеспечение права каждого на зашиту государством его трудовых прав и свобод, включая судебную защиту (ТК) // Жилищное законодательство основывается на необходимости обеспечения органами государственной власти ... условий для осуществления гражданами права на жилище, его безопасности, на неприкосновенности... (ЖК) // Задачами настоящего кодекса являются: ... обеспечение мира и безопасности человечества, а также предупреждение преступлений (УК).

(3.2). Свобода - отсутствие обязанностей: данное значение реализуется в высказываниях, где гражданин выступает как субъект долженствования. Совокупность таких высказываний образует перечень заданных законом ограничений (долженствований) для гражданина - антисвобод: Лишение родительских прав не освобождает родителей от обязанности содержать своего ребенка (СК) // Прекращение членства в объединении работодателей не освобождает работодателя от выполнения соглашения, заключенного в период его членства (ТК) // Гражданин обязан принимать необходимые меры для уведомления своих должников и кредиторов о перемене своего имени и несет риск последствий, вызванных отсутствием у этих лич сведений о перемене его имени (ГК) // При назначении условного осуждения суд устанавливает испытательный срок, в течение которого условно осужденный должен своим поведением доказать свое исправление (УК).

Совокупность разрешительных, запретительных высказываний и высказываний долженствования, составляющих исследуемые тексты, позволяет представить идеальные образы гражданина и государства, формируемые в дискурсивно-жанровой картине мира, реализуемой в тексте кодекса. В основе этих образов лежит соблюдение границ свободы, задаваемых законом.

\section{Заключение}

Концепт свобод $a$ получает в правовой документной коммуникации, в том числе в текстах кодексов, дискурсообразующий статус. Специфика реализации концепта свобода в кодексах РФ определяется ядерным статусом данного жанра в системе письменного правового дискурса, образующего зону взаимодействия правового дискурса и дискурса документа. В результате дикутмная специфика кодекса предполагает реализацию исследуемого концепта в значимом перечне позитивных и негативных социальных действий и состояний, что является результатом реализации модуса правовой оценки. В исследуемых текстах реализуется как базовый модус правового дискурса - модус правовой оценки, так и базовый модус дискурса документа - модус официальности, определяющий равенство всех граждан перед законом (объективность) и обязательность его исполнения (императивность).

Императивность как один из аспектов модуса официальности в текстах кодекса проявлена наиболее последовательно, оформляясь в виде разрешительного, запретительного субмодусов и субмодуса долженствования.

Кодексы охватывают лишь специфические сферы права, обнаруживая диктумную специфику, в связи с чем свобода в кодексах представлена детально, поскольку субъекты ее ограничения/получения вербализуются с большей конкретизацией. Таким образом, каждый кодекс направлен на уточнение границ свободы в соответствии с его диктумной спецификой. 
Кроме того, свобода оказывается связанной с тематическим подразделением кодексов: выделяется семейная, гражданская, трудовая и жилищная свобода. Особый случай составляет Уголовный кодекс, в котором свобода определяется возможностью находиться не под арестом при соблюдении законодательства.

Свобода определяется установкой пользователя на следование закону, что предполагает необхо- димость участвовать в практиках правового дискурса (соблюдать закон), а значит, ограничивать возможности своего поведения, в то время как в русской языковой картине мира свобода не определена.

Соотношения степени активности разрешительного, запретительного субмодусов и субмодуса долженствования определяются также диктумными особенностями кодексов.

\section{Список литературы}

1. Булыгина Т. В., Шмелев А. Языковая концептуализация мира (на материале русской грамматики). М.: Языки славянской культуры, 1997. $577 \mathrm{c}$.

2. Кириллова О. А. Языковая репрезентация лингвокультурного концепта «свобода» в медиа-дискурсе: автореф. дис. ... канд. филол. наук. Ярославль, 2010. 20 с.

3. Солохина А. С. Концепт «свобода» в английской и русской лингвокультурах: автореф. дис. ... канд. филол. наук. Волгоград, 2004. 28 с.

4. Вежбицкая А. Понимание культур через посредство ключевых слов. М.: Языки славянской культуры, 2001. 288 с.

5. Солохина А. С. Свобода // Антология концептов. Т. 1. Волгоград: Парадигма, 2005. С. 222-246.

6. Резанова 3. И. Картины русского мира: современный медиадискурс. Томск: ИД СК-С, 2011. 288 с.

7. Семейный кодекс Российской Федерации. URL: http://www.consultant.ru/document/cons_doc_LAW_8982/ (дата обращения: 12.12.2019).

8. Трудовой кодекс Российской Федерации. URL: http://www.consultant.ru/document/cons_doc_LAW_34683/ (дата обращения: 12.12.2019).

9. Жилищный кодекс Российской Федерации. URL: http://www.consultant.ru/document/cons_doc_LAW_51057/ (дата обращения: 12.12.2019).

10. Гражданский кодекс Российской Федерации. URL: http://base.garant.ru/10164072/ (дата обращения: 12.12.2019).

11. Уголовный кодекс Российской Федерации. URL: http://www.consultant.ru/document/cons_doc_LAW_10699/ (дата обращения: 12.12.2019).

12. Конституция Российской Федерации. URL: http://www.constitution.ru/ (дата обращения: 12.12.2019).

13. Ардашева Т. Г. Лингвокогнитивный анализ концепта «свобода» (на материале русского, английского и французского языков): автореф. дис. ... канд. филол. наук. Ижевск, 2012. 21 c.

14. Ардашева Т. Г., Мерзлякова А. Х. Вербализация концепта «свобода» в юридических текстах // Вестник Удмуртского ун-та. Серия «История и филология», 2011. № 2. С. 13-18.

15. Атабекова А. А., Удина Н. Н. Проблемы реформирования правового дискурса: преодоление трудностей понимания юридического текста // Вестник Московского гос. лингвист. ун-та. 2010. № 27 (606). С. 113-120.

16. Богатырев А. В. Функционирование фигур интертекста в современном юридическом дискурсе: дис. ... канд. филол. наук. Волгоград, 2016. $168 \mathrm{c}$.

17. Власенко Н. А. Язык права. Иркутск: Восточ.-сиб. кн. изд-во: АО Норма-плюс, 1997. 176 с.

18. Косоногова О. В. Юридический дискурс: лингвопрагматика имени собственного // Знание. Понимание. Умение. Проблемы филологии, культурологии и искусствоведения. М.: Московский гуманитарный ун-т, 2008. № 2. С. 188-192.

19. Чернышев А. В. Юридический дискурс и его основные характеристики // Слово.ру: Балтийский акцент. 2016. № 2. С. 22-28.

20. Басенко Г. В. Идеологическая маркированность речевого штампа в текстах конституций России и Германии: прагмалингвистический аспект: автореф. дис. ... канд. филол. наук. Ростов н/Д, 2011. 22 с.

21. Крутихина Т. Е., Юнзель К. Ю. О некоторых стилевых особенностях текста Конституции (на примере текста Конституции ФРГ) // Иностранные языки в контексте культуры: межвузовский сб. ст. по материалам конференции. Пермь, 2011. С. 59-62.

22. Шарикова Л. А., Гейер В. Ю. Особенности юридического мышления через специфику правового дискурса и языка // Вестник Тюменского гос. ун-та. Социально-экономические и правовые исследования. 2008. № 1. С. 96-103.

23. Русакова А. В. Лингвистическая модель двуязычного электронного текстоориентированного словаря юридических терминов (на материале Конституции Российской Федерации, Конституции Французской Республики и Конвенции о защите прав человека и основных Свобод): дис. ... канд. филол. наук. Тюмень, 2008. 198 с.

24. Цзюмин Л. Лингвистические характеристики законодательного текста (на примере Конституции Российской Федерации) // Коммуникативные аспекты языка и культуры: сб. материалов XIV Междунар. научно-практ. конф. студентов и молодых ученых 21-23 мая 2014. 4. 2. Томск, 2014. С. $240-244$.

25. Широбокова Л. П. Юридические тексты: опыт грамматико-типологического исследования на примере немецкого и русского языка: автореф. дис. ... канд. филол. наук. М., 2007. 20 с.

26. Лоскутова К. Н. и др. Язык права в политической лингвистике (тексты советских конституций 1918 и 1936 годов) // Политическая лингвистика. 2011. № 4. С. 217-222.

27. Шмид У. Конституция как прием (риторические и жанровые особенности основных законов СССР и России) // Новое литературное обозрение, 2009. № 6. URL: http://magazines.russ.ru/nlo/2009/100/sh10.html (дата обращения: 01.06.2018). 
Наземиева М. А. Особенности интерпретации свободы в кодексе как ядерном жанре дискурса...

28. Шемберова А. Н. Структурно-содержательные особенности текстов конституций Германии (в диахронии) // Вестник Красноярского гос. пед. ун-та им. В. П. Астафьева. 2011. № 2. С. 221-227.

29. Борисова Л. А. Сравнительный анализ переводов Конституции Российской Федерации на английский язык // Вестн. Воронежского гос. ун-та. 2015. № 2. С. 83-88.

30. Сазонова В. Е. Жанрово-стилистическая специфика текста Конституции США и ее перевод на русский язык, 2016. URL: http://lib.nsu. ru:8081/xmlui/handle/nsu/10667 (дата обращения: 01.06.2018).

31. Баранов В. М., Краснов Д. Г. Кодификация законодательства: теория, практика, техника: материалы Междунар. науч.-практ. конф. (Нижний Новгород, 25-26 сент. 2008 г.): сб. ст. / под ред. В. М. Баранова, Д. Г. Краснова. Н. Новгород, 2009. 1100 с.

32. Храмцова Н. Г. Особенности правового дискурса как системы правовой коммуникации // Вестн. Тюменского гос. ун-та. Социально-экономические и правовые исследования. 2006. № 1. С. 167-173.

33. Храмцова Н. Г. Манипулятивные характеристики правового дискурса в процессе политико-правовой коммуникации (на примере предвыборной кампании в Курганской области) // Вестник Южно-Уральского гос. ун-та. Серия: Социально-гуманитарные науки. 2006. № 2 (57). C. 62-66.

34. Храмцова Н. Г. Концепты «закон» и «субъект права» в правовом дискурсе // Общество и право, 2007. № 4 (18). С. $27-32$.

35. Храмцова Н. Г. Интерпретативная функция правового дискурса // Общество: политика, экономика, право, 2008. № 2. URL: https:// cyberleninka.ru/article/n/interpretativnaya-funktsiya-pravovogo-diskursa (дата обращения: 03.02.2019).

36. Храмцова Н. Г. Правовое мышление и язык права - объективные основания правового дискурса // Пробелы в российском законодательстве. 2009. № 1. С. 54-58.

37. Храмцова Н. Г. Комплексный дискурсивный анализ правового дискурса // Пробелы в российском законодательстве. 2009. № 1. С. $59-62$.

38. Храмцова Н. Г. Правовой дискурс в теории права // Бизнес в законе. Экономико-юридический журнал, 2009. №. 1. С. 80-84.

39. Храмцова Н. Г. Правовой дискурс и дискурсивность права // Российский юридический журнал. 2009. № 5. С. 57-61.

40. Храмцова Н. Г. Опыт применения дискурс-правового анализа к некоторым важнейшим положениям Конституции Российской Федерации // Теория и практика общественного развития, 2013. № 12. URL: https://cyberleninka.ru/article/n/opyt-primeneniya-diskurs-pravovogoanaliza-k-nekotorym-vazhneyshim-polozheniyam-konstitutsii-rossiyskoy-federatsii (дата обращения: 03.02.2019).

41. Храмцова Н. Г. Дискурс-правовой анализ: от теории к практике применения. Курган, 2012. 180 с.

42. Тубалова И. В. Полифонический текст в устных личностно ориентированных дискурсах: дис. ... д-ра филол. наук. Томск, 2015. 539 с.

43. Шмелева Т. В. Смысловая организация предложения и проблема модальности // Актуальные проблемы русского синтаксиса. М., 1984. C. $78-100$.

44. Торгашева М. В. Функционально-стилистические особенности юридического дискурса // Юрислингвистика. 2011. № 11. С. 157-163.

45. Максимов С.И.Концепция правовой реальности // Постклассическая онтология права. СПб., 2016. С. 23-55.

46. Ильин Ю. В., Смирнова И. Ю. Обыденные концепты «good», «bad» как точки роста ментальной области права и суда // Юридическая наука и практика: Вестник Нижегородской академии МВД России. 2017. № 3 (39). С. 66-71.

Наземцева Мария Андреевна, аспирант, Национальный исследовательский Томский государственный университет (пр. Ленина, 36, Томск, Россия, 634050). E-mail: mnazemtseva@gmail.com

Материал поступил в редакциию 30.12.2019.

DOI 10.23951/1609-624X-2020-2-37-48

\section{SPECIFICS OF INTERPRETATION OF FREEDOM IN THE CODE AS A NUCLEAR GENRE OF LEGAL DOCUMENT DISCOURSE}

\section{A. Nazemtseva}

National Research Tomsk State University, Tomsk, Russian Federation

Introduction. The research explored representation of the concept freedom in the Code as a nuclear genre of legal document discourse. Aim and objectives of the article are to identify the specifics of implementation of the concept freedom, defined by modus-dictum organization of legal discourse and the specifics of the Code as its nuclear genre.

Material and methods. The research material consists of the Codes of the Russian Federation, which are Family, Labour, Housing, Civil, and Criminal Codes. The selection of material is determined in accordance with the nuclear status of this genre in legal text. Being one of the main documents of legal discourse, the Code as well as the Constitution of the Russian Federation, reflects the foundations of Russian law. Freedom, as a key concept of Russian culture, is specifically represented in legal discourse. The methodology includes discourse and concept analysis: we observe discursive and genre features from the position of the Code in genre system of legal discourse. Freedom is analyzed through comparing this concept in the system of Russian linguistic world-image on the whole (based on material from studies already conducted) with legal discourse in particular. 
Results and discussion. We found that the concept freedom, in contrast to its common representation in Russian linguistic world-image, has a particular non-binary specificity and is transformed through the law. In everyday language, there is an opposition freedom (will)/unfreedom, and in the Code freedom is realized through a permissive (what can be done within the framework of the law), prohibitive modus (what is criminally punishable and prescribed through unfreedom, i.e. arrest), and a modus of obligation (what is required to be done by law). In addition, freedom in the Codes is influenced by their thematic sphere: there are freedom of family, labour, housing, and civil relationships. In opposition is what is prohibited to do and guarantees unfreedom (represented by the Criminal Code).

Conclusion. Freedom in the legal document discourse is an officially recorded ability of a person to operate within the confines of the law. The Code as a nuclear genre of legal discourse transforms the concept through its modus-dictum modification. As a result, pivotal for the implementation of the concept freedom is the law, as well as the basic concepts of each selected Code - family, labour, housing, citizen, and punishment.

Keywords: concept freedom, Russian linguistic world-image, legal document discourse, genre of the Code, dictum and modus of discourse.

\section{References}

1. Bulygina T. V., Shmelev A. Yazykovaya kontseptualizatsiya mira (na materiale russkoy grammatiki) [Language conceptualization of the world (based on Russian grammar)]. Moscow, Yazyki slavyanskoy kul'tury Publ., 1997. 577 p. (in Russian).

2. Kirillova O. A. Yazykovaya reprezentatsiya lingvokul'turnogo kontsepta "svoboda" v media-diskurse. Avtoref. dis. kand. filol. nauk [Languagespecific representation of the linguistic-cultural concept "freedom" in media discourse. Abstract of thesis of cand. philol. sci.]. Yaroslavl, 2010. 20 p. (in Russian).

3. Solokhina A. S. Kontsept "svoboda" v angliyskoy i russkoy lingvokul'turakh. Avtoref. dis. kand. filol. nauk [Concept "freedom" in the English and Russian linguistic cultures. Abstract of thesis of cand. philol. sci.]. Volgograd, 2004. 28 p. (in Russian).

4. Vezhbitskaya A. Ponimaniye kul'tur cherez posredstvo klyuchevykh slov [Understanding of cultures through the medium of keywords]. Moscow, Yazyki slavyanskoy kul'tury Publ., 2001. 288 p. (in Russian).

5. Solokhina A. S. Svoboda [Freedom]. Antologiya kontseptov. T. 1 [Anthology of concepts. Vol. 1]. Volgograd, Paradigma Publ., 2005. Pp. 222-246 (in Russian).

6. Rezanova Z. I. Kartiny russkogo mira: sovremennyy mediadiskurs [Pictures of the Russian world: a modern media discourse]. Tomsk, ID SK-S Publ., 2011. 288 p. (in Russian).

7. Semeynyy kodeks Rossiyskoy Federatsii [The Family Code of the Russian Federation] (in Russian). URL: http://www.consultant.ru/document/ cons_doc_LAW_8982/ (accessed 12 December 2019).

8. Trudovoy kodeks Rossiyskoy Federatsii [The Labour code of the Russian Federation] (in Russian). URL: http://www.consultant.ru/document/ cons_doc_LAW_34683/ (accessed 12 December 2019).

9. Zhilishchnyyy kodeks Rossiyskoy Federatsii [The Housing Code of the Russian Federation] [Electronic resource] (in Russian). URL: http://www. consultant.ru/document/cons_doc_LAW_51057/ (accessed 12 December 2019).

10. Grazhdanskiy kodeks Rossiyskoy Federatsii [The Civil Code of the Russian Federation] (in Russian). URL: http://base.garant.ru/10164072/ (accessed 12 December 2019).

11. Ugolovnyy kodeks Rossiyskoy Federatsii [The Criminal Code of the Russian Federation] (in Russian). URL: http://www.consultant.ru/document/ cons_doc_LAW_10699/ (accessed 12 December 2019).

12. Konstitutsiya Rossiyskoy Federatsii [The Constitution of the Russian Federation] (in Russian). URL: http://www.constitution.ru/ (accessed 12 December 2019).

13. Ardasheva T. G. Lingvokognitivnyy analiz kontsepta "svoboda" (na materiale russkogo, angliyskogo i frantszuzskogo yazykov). Avroref. dis. kand. filol. nauk [Linguo-cognitive analysis of the concept "Freedom" (based on Russian, English and French languages). Abstract of thesis of cand. philol. sci.]. Izhevsk, 2012. 21 p. (in Russian).

14. Ardasheva T. G., Merzlyakova A. X. Verbalizatsiya kontsepta "svoboda" v yuridicheskikh tekstakh [Verbalization of the concept freedom in legal texts]. Vestnik Udmurtskogo universiteta. Seriya "Istoriya i filologiya" - Bulletin of Udmurt University. History and Philology Series, 2011, no. 2, pp. 13-18 (in Russian).

15. Atabekova A. A., Udina N. N. Problemy reformirovaniya pravovogo diskursa: preodoleniye trudnostey ponimaniya yuridicheskogo teksta [Problems of reforming legal discourse: overcoming difficulties in understanding the legal text]. Vestnik Moskovskogo gosudarstvennogo lingvisticheskogo universiteta - Moscow University Philology Bulletin, 2010, no. 27 (606), p. 113-120 (in Russian).

16. Bogatyrev A. V. Funktsionirovaniye figur interteksta v sovremennom yuridicheskom diskurse. Dis. kand. filol. nauk [Functioning of the intertext figures in modern legal discourse. Diss. cand. philol. sci.]. Volgograd, 2016. 168 p. (in Russian).

17. Vlasenko N. A. Yazyk prava [Language of Law]. Irkutsk, Vostoch.-sib. kn. izd-vo, Norma-plyus Publ., 1997. 176 p. (in Russian).

18. Kosonogova O. V. Yuridicheskiy diskurs: lingvopragmatika imeni sobstvennogo [Legal discourse: linguopragmatics of the proper name]. Znaniye. Ponimaniye. Umeniye. Problemy filologii, kul'turologii i iskusstvovedeniya - Knowledge. Understanding. Skill. Problems of philology, cultural studies and art history. Moscow, Moscow University for the Humanities Publ., 2008, no. 2, pp. 188-192 (in Russian).

19. Chernyshev A. V. Yuridicheskiy diskurs i ego osnovnye kharakteristiki [Legal discourse and its main characteristics]. Slovo.ru: Baltiyskiy aktsent - Slovo.ru: Baltic Accent, 2016, no. 2, pp. 22-28 (in Russian). 
20. Basenko G. V. Ideologicheskaya markirovannost' rechevogo shtampa v tekstakh konstitutsiy Rossii i Germanii: pragmalingvisticheskiy aspekt. Avtoref. dis. kand. filol. nauk [ldeological marking of the speech stamp in the texts of the Constitutions of Russia and Germany: the pragmalinguistic aspect. Abstract of diss. cand. philol. sci.]. Rostov-on-Don, 2011. 22 p. (in Russian).

21. Krutikhina T. E., Yunzel' K. Yu. O nekotorykh stilevykh osobennostyakh teksta Konstitutsii (na primere teksta Konstitutsii FRG) [About some stylistic features of the text of the Constitution (the case of the text of the Constitution of Germany)]. Inostrannye yazyki v kontekste kul'tury: mezhvuzovskiy sbornik statey po materialam konferentsii [Foreign languages in the context of culture: interuniversity collection of articles based on conference materials]. Perm, 2011. Pp. 59-62 (in Russian).

22. Sharikova L. A., Geyer V. Yu. Osobennosti yuridicheskogo myshleniya cherez spetsifiku pravovogo diskursa i yazyka [Features of legal thinking through the specifics of legal discourse and language]. Vestnik Tyumenskogo gosudarstvennogo universiteta. Sotsial'no-ekonomicheskiye $i$ pravovye issledovaniya - Tyumen State University Herald. Social, Economic, and Law Research, 2008, no. 1, pp. $96-103$ (in Russian).

23. Rusakova A.V. Lingvisticheskaya model' dvuyazychnogo elektronnogo tekstooriyentirovannogo slovarya yuridicheskikh terminov (na materiale Konstitutsii Rossiyskoy Federatsii, Konstitutsii Frantszuzskoy Respubliki i Konventsii o zashchite prav cheloveka i osnovnykh svobod). Dis. kand. filol. nauk [Linguistic model of a bilingual electronic text-based dictionary of legal terms (based on the material of the Constitution of the Russian Federation, the Constitution of the French Republic and the Convention for the Protection of Human Rights and Fundamental Freedoms). Diss. cand. philol. sci.]. Tyumen, 2008. 198 p. (in Russian).

24. Czzyumin L. Lingvisticheskie xarakteristiki zakonodatel'nogo teksta (na primere Konstitucii Rossijskoj Federacii) [Linguistic characteristics of the legislative text (the case of the Constitution of the Russian Federation)]. Kommunikativnye aspekty yazyka i kul'tury: sb. materialov XIV Mezhdunar. nauchno-prakt. konf. studentov i molodykh uchenykh 21-23 maya 2014. Ch. 2 [Communicative aspects of language and culture: a collection of materials of the XIV International scientific and practical conference of students and young scientists on May 21-23, 2014. Part 2]. Tomsk, 2014. Pp. 240-244 (in Russian).

25. Shirobokova L. P. Yuridicheskiye teksty: opyt grammatiko-tipologicheskogo issledovaniya na primere nemetszkogo i russkogo yazyka. Avtoref. dis. kand. filol. nauk [Legal texts: experience of grammar-typological research through the example of German and Russian language. Abstract of thesis of cand. philol. sci.]. Moscow, 2007. 20 p. (in Russian).

26. Loskutova K. N. et all. Yazyk prava v politicheskoy lingvistike (teksty sovetskikh konstitutsiy 1918 i 1936 godov) [Language of law in political linguistics (texts of the Soviet Constitutions of 1918 and 1936)]. Politicheskaya lingvistika - Political Linguistics, 2011, no. 4, pp. 217-222 (in Russian).

27. Shmid U. Konstitutsiya kak priyem (ritoricheskiye i zhanrovye osobennosti osnovnykh zakonov SSSR i Rossii) [Constitution as a technique (rhetorical and genre features of the basic laws of the USSR and Russia)]. Novoye literaturnoye obozreniye, 2009, no. 6 (in Russian). URL: http:// magazines.russ.ru/nlo/2009/100/sh10.html (accessed 1 June 2018).

28. Shemberova A. N. Strukturno-soderzhatel'nye osobennosti tekstov Konstitutsiy Germanii (v diakhronii) [Structural and substantial features of the texts of the German Constitutions (in diachrony)]. Bulletin of Krasnoyarsk State Pedagogical University, 2011, no. 2, pp. 221-227 (in Russian).

29. Borisova L. A. Sravnitel'nyy analiz perevodov Konstitutsii Rossiyskoy Federatsii na angliyskiy yazyk [A comparative analysis of the translations of the Constitution of the Russian Federation into English]. Vestnik Voronezhskogo gosudarstvennogo universiteta - Proceedings of the Voronezh State University, 2015, no. 2, pp. 83-88 (in Russian).

30. Sazonova V. E. Zhanrovo-stilisticheskaya spetsifika teksta Konstitutsii SShA i eye perevod na russkiy yazyk [Genre-stylistic specifics of the text of the US Constitution and its translation into Russian]. 2016 (in Russian). URL: http://lib.nsu.ru:8081/xmlui/handle/nsu/10667 (accessed 1 June 2018).

31. Baranov V. M., Krasnov D. G. Kodifikatsiya zakonodatel'stva: teoriya, praktika, tekhnika [Codification of legislation: theory, practice, technology]. Materialy Mezhdunarodnoy nauchno-prakticheskoy konferentsii (Nizhniy Novgorod, 25-26 sent. 2008 g.): sb. st. [Materials of the International scientific-practical conference (Nizhny Novgorod, September 25-26, 2008): proceedings. Ed. V. M. Baranova, D. G. Krasnova]. Nizhny Novgorod, 2009. 1100 p. (in Russian).

32. Khramtsova N. G. Osobennosti pravovogo diskursa kak sistemy pravovoy kommunikatsii [Features of legal discourse as a system of legal communication]. Vestnik Tyumenskogo gos. un-ta. Sotsial'no-ekonomicheskiye i pravovye issledovaniya - Tyumen State University Herald. Social, Economic and Law Research, 2006, no. 1, pp. 167-173 (in Russian).

33. Khramtsova N. G. Manipulyativnye kharakteristiki pravovogo diskursa v protsesse politiko-pravovoy kommunikatsii (na primere predvybornoy kampanii v Kurganskoy oblasti) [Manipulative characteristics of legal discourse in the process of political and legal communication (the case of the election campaign in the Kurgan region)]. Vestnik Uzhno-Ural'skogo gosudarstvennogo universiteta. Seriya: Sotsial'no-gumanitarnye nauki - Bulletin of the South Ural State University. Series "Social Sciences and the Humanities", 2006, no. 2 (57), pp. $62-66$ (in Russian).

34. Khramtsova N. G. Kontsepty "zakon" i "sub"ekt prava" v pravovom diskurse [Concepts "Law" and "Subject of Law" in legal discourse]. Obshchestvo i pravo - Society and Law, 2007, no. 4 (18), pp. 27-32 (in Russian).

35. Khramtsova N. G. Interpretativnaya funktsiya pravovogo diskursa [Interpretative function of legal discourse]. Obshchestvo: Politika, ekonomika, Pravo - Society: Politics, Economics, Law, 2008, no. 2 (in Russian). URL: https://cyberleninka.ru/article/n/interpretativnaya-funktsiya-pravovogodiskursa (accessed 3 February 2019).

36. Khramtsova N. G. Pravovoye myshleniye i yazyk prava - ob"ektivnye osnovaniya pravovogo diskursa [Legal thinking and the language of law are the objective grounds for legal discourse]. Probely v rossiyskom zakonodatel'stve, 2009, no. 1, pp. 54-58 (in Russian).

37. Khramtsova N. G. Kompleksnyy diskursivnyy analiz pravovogo diskursa [A comprehensive review of legal discourse]. Probely $v$ rossiyskom zakonodatel'stve, 2009, no. 1, pp. 59-62 (in Russian). 
38. Khramtsova N. G. Pravovoy diskurs v teorii prava [Legal discourse in the theory of law]. Biznes v zakone. Ekonomiko-yuridicheskiy zhurnalBusiness in law. Journal of Economics and Law, 2009, no. 1, pp. 80-84 (in Russian).

39. Khramtsova N. G. Pravovoy diskurs i diskursivnost' prava [Legal discourse and discursiveness of law]. Rossiyskiy yuridicheskiy zhurnal - Russian Juridical Journal, 2009, no. 5, pp. 57-61 (in Russian).

40. Khamtsova N. G. Opyt primeneniya diskurs-pravovogo analiza k nekotorym vazhneyshim polozheniyam Konstitutsii Rossiyskoy Federatsii [An experience of applying discourse and legal analysis to some of the most important provisions of the Constitution of the Russian Federation]. Teoriya i practika obshchestvennogo razvitiya - Theory and Practice of Social Development, 2013, no. 12 (in Russian). URL: https://cyberleninka. ru/article/n/opyt-primeneniya-diskurs-pravovogo-analiza-k-nekotorym-vazhneyshim-polozheniyam-konstitutsii-rossiyskoy-federatsii (accessed 3 February 2019).

41. Khramtsova N. G. Diskurs-pravovoy analiz: ot teorii k praktike primeneniya [Discourse-legal analysis: from theory to practical application]. Kurgan, 2012. 180 p. (in Russian).

42. Tubalova I. V. Polifonicheskiy tekst $v$ ustnykh lichnostno oriyentirovannykh diskursakh. Dis. dokt. filol. nauk [Polyphonic text in oral personalityoriented discourses. Diss. doct. philol. sci.]. Tomsk, 2015. 593 p. (in Russian).

43. Shmeleva T. V. Smyslovaya organizatsiya predlozheniya i problema modal'nosti [Semantic organization of sentences and the problem of modality]. In: Aktual'nye problemy russkogo sintaksisa [Topical issues of Russian syntax]. Moscow, 1984, pp. 78-100 (in Russian).

44. Torgasheva M. V. Funktsional'no-stilisticheskiye osobennosti yuridicheskogo diskursa [Functional and stylistic features of legal discourse]. Yurislingvistika - Legal Linguistics, 2011, no. 11, pp. 157-163 (in Russian).

45. Maksimov S. I. Kontseptsiya pravovoy real'nosti [Concept of legal reality]. Postclassical ontology of law [Postclassical ontology of law]. Saint Petersburg, 2016. Pp. 23-55 (in Russian).

46. Il'in Yu. V., Smirnova I. Yu. Obydennye kontsepty "good", "bad" kak tochki rosta mental'noy oblasti prava i suda [Ordinary language concepts of "good", "bad" as growth points of the mental field of law and court]. Yuridicheskaya nauka i praktika: Vestnik Nizhegorodskoy akademmii MVD Rossii - Journal of Nizhny Novgorod Academy of Ministry of Internal Affairs of Russia, 2017, no. 3 (39), pp. 66-71 (in Russian).

Nazemtseva M. A., National Research Tomsk State University (pr. Lenina, 36, Tomsk, Russian Federation, 634050).

E-mail: mnazemtseva@gmail.com 